\title{
Strength Properties of Fibre Reinforced High Performance Concrete Blended with Metakolin and Condensed Silica Fume.
}

\author{
M. Bhaskar ${ }^{1}$, P. Srinivasa Rao ${ }^{2}$, B.L.P Swami ${ }^{3}$ \\ ${ }^{I}$ Assistant Professor, Department Civil Engineering Department, Vasavi College of Engineering, Ibrahimbagh, \\ Hyderabad-500031, (INDIA) \\ ${ }^{2}$ Professor, Civil Engineering, JNTU. College of Engineering, Kukatpalli, Hyderabad (INDIA) \\ ${ }^{3}$ Professor and Co-ordinator, Research and Consultancy, Vasavi College of Engineering, Ibrahimbagh, \\ Hyderabad-500031, (INDIA)
}

\begin{abstract}
In the case of high performance concrete with strengths above M50, additions of small percentages of fibres contribute towards higher strengths especially in tension and flexure. Mineral admixtures used as part replacement to cement yield better workability and strength of concrete. In the present experimental investigation, mineral admixtures like condensed silica fume and Metakaoline are used as part replacement of ordinary Portland cement in M60 Concrete. Steel fibres of constant aspect ratio were used at different percentages varying from 0.0 to 1.5 in four steps. In total 20 cominations of admixtured fibrous concrete were prepared and tested for compressive, tensile and flexural strengths.The results have shown that optimum properties for high performance concrete (HPC) can be developed by employing suitable mineral admixtures with fibre reinforcement.
\end{abstract}

Keywords: HPC, DOE method, Mineral admixtures, fibre percentage fineness, optimum strength.

\subsection{Production Of Hpc:}

\section{Introduction}

High strength concrete is used extensively throughout the world in the oil, gas, nuclear and power industries etc.. The application of such concrete is increasing day by day due to their superior structural performance, environmental friendliness and energy conserving implications. Apart from the usual risk of fire, these concretes are exposed to high temperatures and pressures for considerable periods of times in the above mentioned industries. High-Performance concrete is specified where reduced weight is important or where architectural considerations call for small support elements. By carrying loads more efficiently than normalstrength concrete, high-performance concrete also reduces the total amount of material placed and lowers the overall cost of the structure. High-strength concrete columns can hold more weight and therefore be made slimmer than regular strength concrete columns, which allow for more usable space, especially in the lower floors of buildings. High Strength Concretes are also used in other engineering structures like bridges.

From the general principles behind the design of high-strength concrete mixtures, it is apparent that high strengths are made possible by reducing porosity, inhomogeneity, and micro cracks in the hydrated cement paste and the transition zone.Applications of mineral admixtures such as silica fume, metakaoline and ground granulated blast furnace slag in concrete are effective to increase the strength durability in high strength concrete. The addition of admixtures to the concrete mixture increases the strength by pozzolonic action and filling in the small voids that are created between cement particles. Thus the performance of concrete is very much increased with more strength, good workability and better durability to produce high performance concrete (HPC).

\subsection{Use of Fibre Reinforcement:}

Fibre Reinforced Concrete is a concrete composed of normal setting hydraulic cements, fine and coarse aggregates and discontinuous discrete fibre with different proportions, different length and different gauges as parameters. When the loads imposed on concrete approach that for failure, cracks will propagate, sometimes rapidly. Fibres in concrete provide a means of arresting the crack growth. Short discontinuous fibres have the advantage however of being uniform. If the modulus of elasticity of the fiber is high with respect to the modulus of elasticity of the concrete or mortar binder, the fibres help to carry the load, there by increasing the tensile strength of the material. Increases in the length, diameter ratio of the fibers usually augment the flexural strength and toughness of the concrete. 


\subsection{Pozzolonie admixtures in concrete:}

Pozzolonas are either naturally occurring or available as waste materials. They mainly contain silica, which comes reactive in the presence of free lime available in cement when pozzolonic admixtures are mixed with cement. The reactivity varies depending upon the type of pozzolana, its chemical composition and its fineness. In developing countries like India, pozzolonic materials are mainly available as industrial waste byproducts. Flyash, silica fume, stone dust, blast furnace slag, rice husk ash, etc., are some of industrial wastes and metakaoline is a quality controlled reactive Pozzolona, made from purified kaolin which possesses pozzolonic properties.

\subsection{Brief Review}

Bai and wild studied (4).The workability property of concrete with metakaoline and fuelash. Coldrone, M.A et al (7.) have studied the properties of HPC with metakaoline and reported good results. Ding, J.T at al (9.) have reported the improved properties of concrete with mineral admixtures like silica fume and metakaoline.

\subsection{Details of Present Investigation:}

In the present experimental investigation, high Performance concrete with a base concrete mix of M60 has been developed with optimum properties. To arrive at these active mineral admixtures like Condensed Silica Fume(CSF) and Metakaoline one added in varying prosperities along with steel fibre at different percentages. Thus, a mix consisting of triple blending with fibres has been developed to have optimum strength and durability properties.

1.6 Materials.

\section{Experimental Investigation.}

The following materials were used in the experimentation.

\subsubsection{Cement}

Ordinary Portland Cement (OPC) 53 grade. of M/s. Ultra Tech Cement Ltd was used for concrete mixes. Its specific gravity is 3.00 and it satisfied all the requirements of I.S. Code.

\subsubsection{Fine aggregate.}

Locally available river sand with a specific gravity of 2.68 and fineness modules of 2.78 was used.

\subsubsection{Coarse Aggregate.}

Machine crushed granite aggregate of $20 \mathrm{~mm}$ nominal size were used. The specific gravity is 2.70 and the fineness modulus is 7.14. Both the fine and course aggregate were tested in accordance with IS 2386 and IS383-2016.

\subsubsection{Metakaolin.}

Meta Kaolin satisfies the requirements of Pozzolona. It is a fine mineral admixture very much suitable to use at certain percentage as a partial replacement to OPC. It was obtained from M/s. 20 Microns Limited, Vadodara. Its specific gravity is 2.54 and fineness is above $10,000 \mathrm{~cm}^{2} / \mathrm{gm}$ : It has an active silica content of $51-53 \%$.

\subsubsection{Condensed Silica Fume(CSF)}

CSF was obtained from M/S V B Ferro Alloys Ltd near Hyderabad. It is very fine amorphous material with Blaine's fineness more than $10,000 \mathrm{~cm}^{2} / \mathrm{gm}$.

\subsubsection{Steel Fibers}

Mild steel fibers of $0.9 \mathrm{~mm}$ diameter with an aspect ratio between 40 to 50 were employed.

\subsubsection{Water}

Portable water was used in the investigation.

\subsubsection{Superplasticizer}

Superplasticizer (SP-430) of M/S Fosrock India ltd was used.

\subsection{Mix Design for M60}

DOE method (Adopted by the B.S. Code) has been used for the design of high strength concrete mix. The details of the mix are shown in the table. 1

Table.1 Details of M60 Concrete Mix (Reference).

\begin{tabular}{|l|l|l|l|l|}
\hline Concrete Mix M60 & Cement & Fine Aggregate & Coarse Aggregate & Water. \\
\hline Proportions & 1 & 1.07 & 1.75 & 0.33 \\
\hline $\begin{array}{l}\text { Quantities required } \\
\text { for 1.c.m of cement. }\end{array}$ & $590.94 \mathrm{~kg}$ & $597.21 \mathrm{~kg}$ & $1016.88 \mathrm{~kg}$ & 195 litres. \\
\hline
\end{tabular}




\subsection{Percentages of Mineral Admixtures.}

In the present experimental investigation triple blending has been carried out by using two admixtures CSF and Metakaolin as replacement to OPC. The percentage replacements by both the admixtures were varied between $o$ to 15 (optimum values).

\subsection{Percentages of steel fibre.}

Steel Fiber Reinforcement at varying percentages from o to 1.5 was used in the various mixes. The diameter of the mild steel fiber is $0.9 \mathrm{~mm}$ and the aspect ratio is $40-50$.

\subsection{Concrete Mix Combinations.}

By varying the percentages of mineral admixtures and steel fibres, 20 no's of combinations of concrete mixes were tired in the investigation.

\subsection{Workability Tests.}

The workability test was conducted on all the mixes by using the compactions factor apparatus. It was found that the compacting factor values were somewhat low and with fibre reinforcement the values tended to be lower. With the presence of mineral admixtures there is some improvement in the C.F values, but on the whole the workability was low. Workability was improved by adding superplasticizer $(0.5$ to $1 \%)$.

\subsection{Concrete Mixing, Compacting.}

All the combinations of concrete mixes were mixed well by using a pan mixer and cast in the standard moulds, compactions was carried out with the help of table vibrator. After 24 hours, of air drying, demolding was carried out and the specimens were water cured. At the ages of 7 and 28 days the specimens were taken out of the curing tank, dried and tested. Sufficient number of standard specimens (Cubes, Cylinders and Prisms) was prepared by following standard procedures.

\subsection{Tests.}

Tests on the specimens were carried out for compressive strength, split tensile strength and flexural strength. Standard procedures were followed for conducting the tests.

\subsection{Presentation of Results.}

\section{Discussion Of The Test Results.}

The Compressive strength results are presented in table 2 for all the 20 nos of combinations. The results of split tensile strength and flexural strength are plotted. Typical plots for 1.0 percent fibre are shown in figs. 1 to 4 respectively.

\subsection{Compressive Strength:}

It has been observed that with the addition of Metakaolin and Silica fume the initial strength of concrete at 7 days has increased very much with various proportions of the mix. The increase in strength has been in the range of $37.64 \%-49.11 \%$ of M0 (0\% admixture replacement). This high initial strength can be attributed to the rapid setting property of the admixtures. However, the 28day strength of the concrete mixes is closer to the reference mix. The increase in strength is in the range of $2 \%-21 \%$. On analyzing the tested specimens it was found that the bonding between the concrete materials is of very high quality. The compressive strength is highest for mix with partial replacement of cement by 10\% Silica Fume and 5\% Metakaolin for mixes without fibres. For mixes with fibres, the compressive strength is highest for mix with partial replacement of cement by $10 \%$ silica fume and 5\% Metakaolin, with a fiber addition of $1.5 \%$.

\subsection{Split Tensile Strength:}

For mixes with zero fibres, it has been observed that with addition of silica fume and Metakaolin the split tensile strength of concrete at 28 days has increased slightly by $2-15 \%$. But for the mixes involving Metakaolin at higher percentage of replacement the strength has decreased when compared to mixes with lower replacement with Metakaolin.With the partial replacement of cement by $10 \%$ of silica fume and $5 \%$ of Metakaolin it is observed that the 28 days split tensile strengths are high. As the fiber \% increases the split tensile strengths also increases. With $1.5 \%$ of fibres in the mix containing $10 \%$ of silica fume and $5 \%$ of Metakaolin the split tensile strength is highest. Hence it is clear that the presence of fibers is contributing towards increase in split tensile strength. It is also noted that all the triple blended mixes are giving the design strength.

\subsection{Flexural Strength:}

It has been observed that with addition of silica fume and metakaolin and with the increase in \% fibres, flexural strengths of concrete at 7 days and 28 days have increased considerably by $1-20 \%$. With the partial replacement of cement by $10 \%$ silica fume, $5 \%$ Metakaolin and for $0.0,0.75,1.0 \mathrm{and}, 1.5 \%$ of fibres the flexural strength at 7 days is increased by $6-18 \%$ and at 28 days it is $17-22 \%$ gain. It has been observed that as the fiber $\%$ increases the flexural strengths also increases. Hence it is clear that the presence of fibers is contributing towards increase in flexural strengths. 


\subsection{Advantages of Triple Blending}

On the whole, it can be observed that triple blending of OPC, CSF and Metakaoilin has yielded higher strengths compared to the reference Mix.it can be seen that the optimum combination of the admixtures is $15 \%$.Hence,triple blending helps in the production of HPC. In addition,by resorting to triple blending better workability,strength and durability are achived in producing an optimum HPC mix.

Table 2: Results of Compressive Strength at 7 and 28 days.

\begin{tabular}{|c|c|c|c|c|c|c|c|}
\hline $\begin{array}{l}\text { Mix } \\
\text { no. }\end{array}$ & $\begin{array}{l}\text { CSF } \\
\text { Percentage }\end{array}$ & $\begin{array}{l}\text { Metakaolin } \\
\text { Percentage }\end{array}$ & $\begin{array}{l}\text { Fibre } \\
\text { Percentage }\end{array}$ & $\begin{array}{l}\text { 7days } \\
\text { Compressive } \\
\text { Strength } \\
\end{array}$ & $\begin{array}{l}\mathbf{N} / \mathbf{m m}^{2} \\
\text { Percentage } \\
\text { increase }\end{array}$ & $\begin{array}{l}\text { 28days } \\
\text { Compressive } \\
\text { Strength } \\
\end{array}$ & $\begin{array}{l}\text { Percentage } \\
\text { increase }\end{array}$ \\
\hline 1 & 0 & 0 & 0.0 & 44.92 & - & 67.39 & - \\
\hline 2 & 15 & 0 & 0.0 & 61.83 & 37.64 & 68.75 & 2.01 \\
\hline 3 & 0 & 15 & 0.0 & 64.55 & 43.61 & 74.30 & 10.25 \\
\hline 4 & 5 & 10 & 0.0 & 64.00 & 42.47 & 77.90 & 15.59 \\
\hline 5 & 10 & 5 & 0.0 & 66.98 & 49.11 & 81.50 & 20.94 \\
\hline 6 & 0 & $\mathbf{0}$ & 0.75 & 45.47 & - & 68.90 & - \\
\hline 7 & 15 & $\mathbf{0}$ & 0.75 & 64.81 & 42.53 & 70.49 & 2.3 \\
\hline 8 & 0 & 15 & 0.75 & 58.73 & 29.16 & 73.41 & 6.50 \\
\hline 9 & 5 & 10 & 0.75 & 53.06 & 16.69 & 72.10 & 4.64 \\
\hline 10 & 10 & 5 & 0.75 & 53.61 & 17.9 & 74.00 & 7.40 \\
\hline 11 & 0 & 0 & 1.05 & 46.33 & - & 70.20 & - \\
\hline 12 & 15 & 0 & 1.05 & 57.65 & 24.43 & 73.12 & 4.12 \\
\hline 13 & 0 & 15 & 1.05 & 57.79 & 24.73 & 70.79 & 0.008 \\
\hline 14 & 5 & 10 & 1.05 & 54.51 & 17.65 & 77.00 & 9.68 \\
\hline 15 & 10 & 5 & 1.05 & 51.96 & 12.15 & 76.20 & 8.54 \\
\hline 16 & 0 & 0 & 1.5 & 51.68 & - & 72.30 & - \\
\hline 17 & 15 & $\mathbf{0}$ & 1.5 & 53.60 & 3.70 & 74.10 & 2.48 \\
\hline 18 & 0 & 15 & 1.5 & 55.70 & 7.70 & 77.56 & 7.27 \\
\hline 19 & 5 & 10 & 1.5 & 52.70 & 1.97 & 78.50 & 8.57 \\
\hline 20 & 10 & 5 & 1.5 & 54.50 & 5.40 & 78.50 & 8.57 \\
\hline
\end{tabular}

\subsection{Use of Steel Fibers in HPC}

When the mineral admixures help in producing an optimum HPC mix, addition of a small percentage of steel fibers help in deriving better tensile and flexural strengths. The steel fibers also helps in controlling the shrinkage cracks in concrete.Hence,the use of optimum percentages of mineral admixtures together with a small percentage of steel fiber would produce HPC with alround benefits.

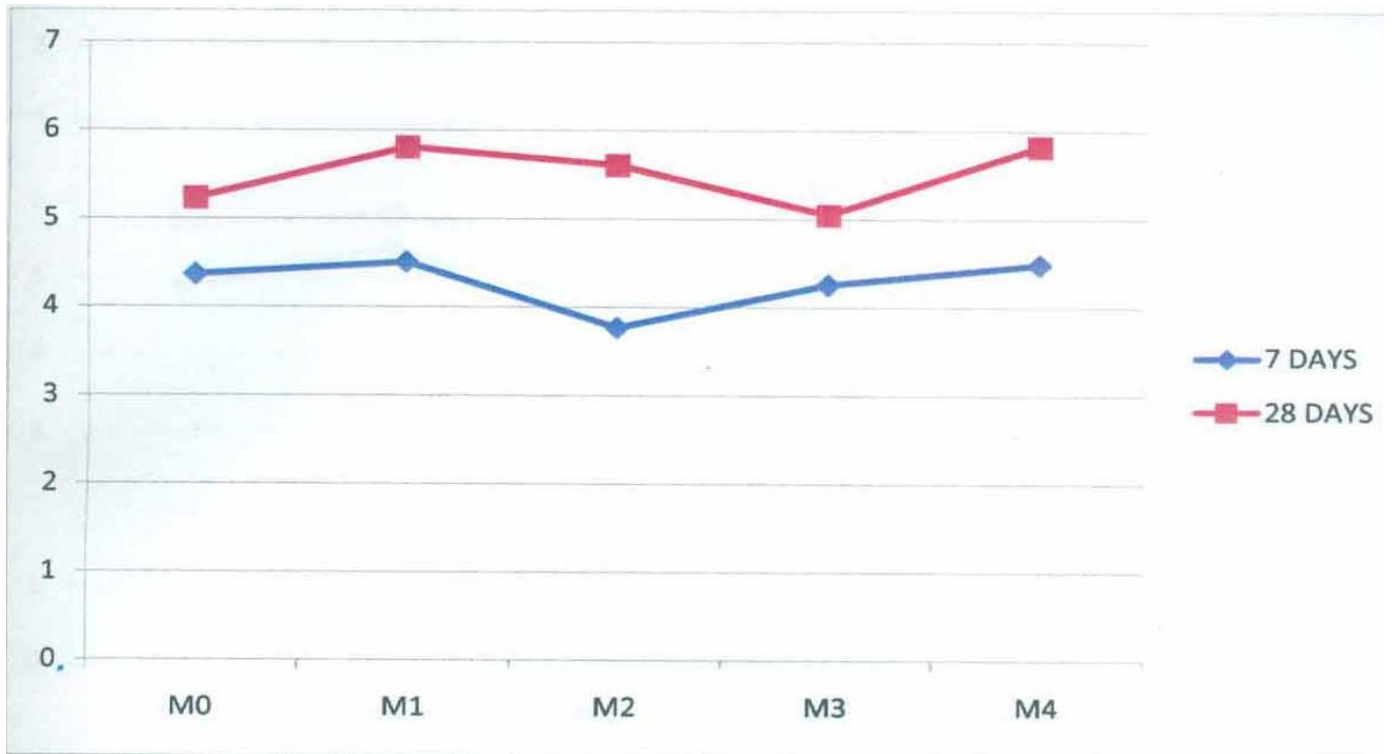

Fig 1: Split tensile strength of blended concrete mixes (M60) for different total admixture percentages for $1 \%$ fibers. 


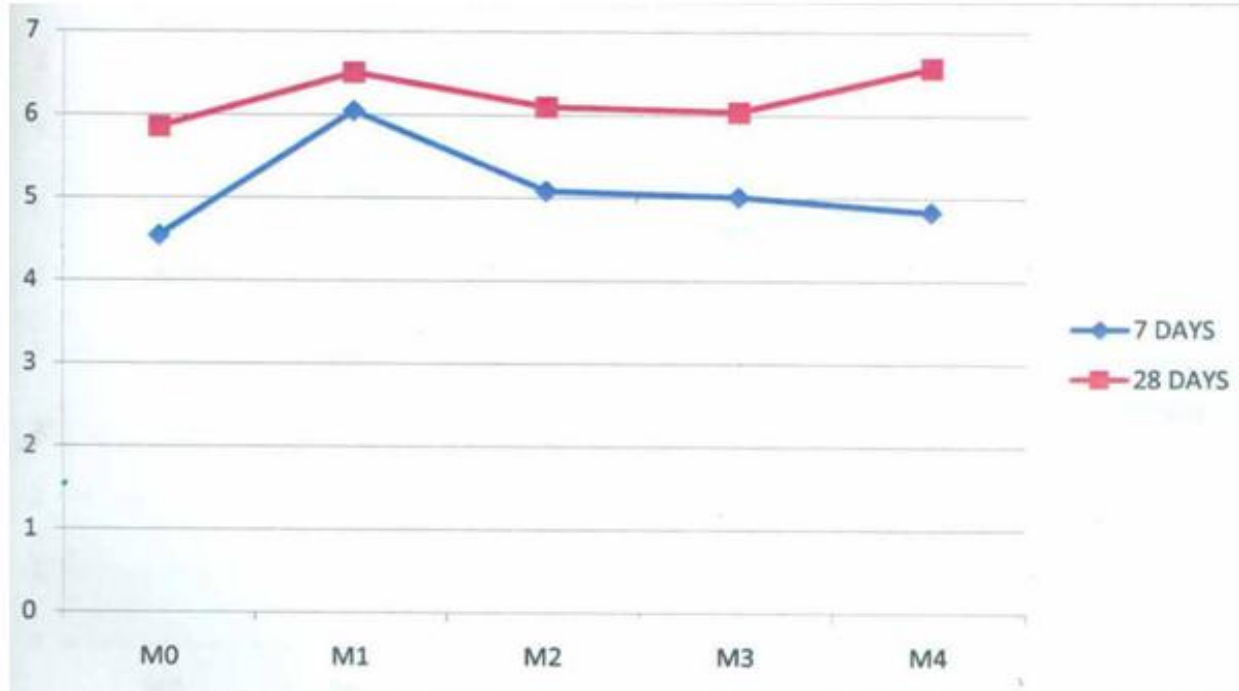

Fig 2: Split tensile strength of blended concrete mixes (M60) for different total admixture percentages for $1.5 \%$ fibres.

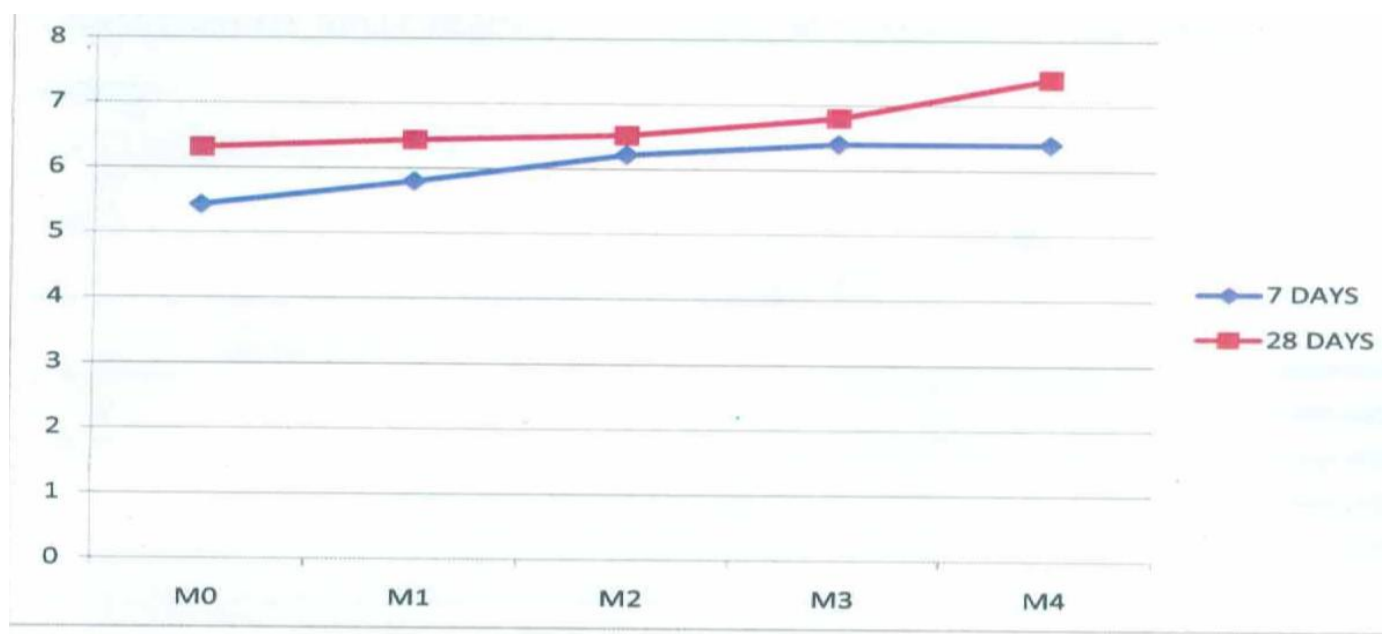

Fig 3: Flexure strength of blended concrete mixes(M60) for different total admixture percentages for $1 \%$.

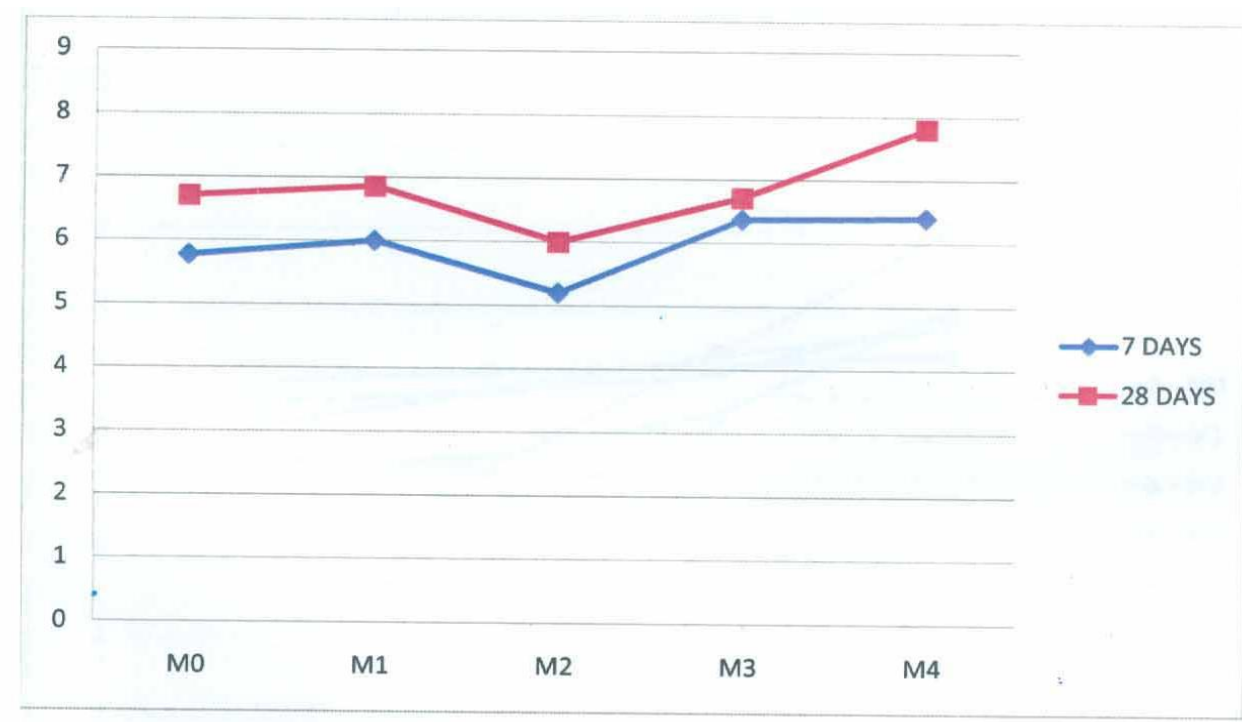

Fig 4: Flexure strength of blended concrete mixes (M60) for different total admixture percentages for $1.5 \%$ fibre International Conference on Recent Innovations in Civil \& Mechanical Engineering $103 \mid$ Page [i-CAM2K16] DOI: 10.9790/1684-160530199105 


\section{Conclusion}

Based on the experimental study undertaken the following conclusions are drawn.

1. An effective and efficient triple blended concrete mix can be prepared with the addition of condensed silica fume and Metakaolin to OPC. This triple blended mix is not only cost effective also it renders the concrete to achieve several beneficial properties.

2. When the mineral admixtures like silica fume or Metakaolin and steel fibres are added at higher percentages to cement, the workability of concrete (M60) is getting reduced. There is a need to add small dosage of $0.5 \%-1 \%$ of superplasticizer to maintain constant medium workability.

3. In the case of triple blended concrete $10 \%$ CSF \& 5\% MK give highest strength without fiber reinforcement.

4. Because of the higher reactivity of Metakaolin the 7 day strengths are found to be higher compared to the reference mix. As the $\%$ of fibre increases the compressive strength also further increased. The highest compressive strength for fiber mixes is obtained with $10 \%$ CSF \& $5 \%$ Metakaolin and $1.5 \%$ steel fibre. This is more than the compressive strength of reference concrete by $8-10 \%$. The compressive strength values for other combinations are in between.

5. The Split tensile strength is more in the case of triple blended concrete. Highest tensile strength is obtained with $10 \% \mathrm{CSF}$ and $5 \% \mathrm{MK}$. this is more than the reference mix by $18 \%$. The values are in between for other combinations.

6. The Highest tensile strength is obtained with 10\% CSF and 5\% Metakaolin with1.5\% fibres. This is more by nearly $45 \%$ compared to reference mix.

7. The Flexural strengths are also higher for triple blended concretes with various combinations. These values are further increased with addition of fibres.

8. Without fibres for a combination of $10 \%$ CSF and 5\% Metakaolin the flexural strength is higher than the reference by $18 \%$. For other combinations the increase is in between.

9. The highest flexural strength with $10 \%$ CSF , 5\% Metakaolin and $1.5 \%$ fiber is nearly $36 \%$ more than that of reference mix.

10. With optimum percentage of mineral admixtures and with a small percentage of steel fibre, HPC with alround benefits can be produced.

\section{Acknowledgements}

The Authors Convey Their Thankfulness To The Authorities Of Vasavi College Of Engineering, Hyderabad For Permitting To Use The Laboratory Facilities Of The College.

\section{References}

[1]. Aquino, W., Lange, D.A. and Olek, J. (2001), The influence of metakaoline and silica fume on the chemistry of alkali-silica reaction products, Cement and Concrete Composites, 23(6): 485-493.

[2]. Asbridge, A.H., Chadbourn, G.A and Page, C.L. (2001), Effects of metakaoline and the infterfacial transition zone on the diffusion of chloride ions through cement mortars, Cement and Concrete Research, 31(11): 1567-1572.

[3]. Bai, J. and Wild, S. (2002), Investigation of the temperature change and heat evolution of mortar incorporating PFA and metakaoline, Cement and Concrete Composites, 24(2): 201-209.

[4]. Bai, J., Wild, S., Sabir, B.B. and Kinuthia, J.M. (1999), Workability of concrete incorporating pulverized fuel ash metakaoline, Magazine of Concrete Research, 51(3): 207-216.

[5]. Batis, G., Pantazopoulou, P., Tsivilis, S. and Badogiannis, E. (2004), The effect of metakaoline on the corrosion behavior of cement mortars, Cement and Concrete Composites, in press.

[6]. Brooks, J.J. and johari, M.A.M (2001), Effect of metakaoline on creep and shrinkage of concrete, Cement and Concrete Composites, 23(6): 495-502.

[7]. Caldarone, M.A., Gruber, K.A and Burg, R.G. (1994), High reactivity metakaoline (HRM): a new generation mineral admixture for high performance concrete, Concrete International, 16(11): 37-40.

[8]. Curcio, F., DeAngelis, B.A. and Pagliolico, S. (1998), Metakaoline as a pozzolonic microfiller for high-performance mortars, Cement and Concrete Research, 28(6): 803-809.

[9]. Ding, J.T. and Li, Z.J. (2002), Effects of metakaoline and silica fume on properties of concrete, ACI Materials Journal, 99(4): 393-398.

[10]. Frias, M., de Rojas, M.I.S and Cabrera, J. (2000), The effect that the pozzolonic reaction of metakaoline has on the heat evolution in metakaoline-cement mortars, Cement and Concrete Research, 30(2): 209-216.

[11]. Gruber, K.A., Ramlochan, T., Boddy, A., Hooton, R.D. and Thomas, M.D.A (2001), increasing concrete durability with high-reactivity metakaoline, Cement and Concrete Composites, 23(6): 479-484.

[12]. Jeim Tong Ding and Zongjin Li,"

[13]. "Effects of Metakaoline and silica Fume on properties of Concrete" A.C.I. Materials Journal, July- August 2002.

[14]. Khatib, J.M. and Clay, R.M. (2003), Absorption characteristics of metakaoline concrete, Cement and Concrete Research, in press. 
[15]. Khatib, J.M., Hibbert, J.J. (2004), selected engineering properties of concrete incorporating metakaoline and slag, Construction and Building Materials, in press.

[16]. Rofat Siddique: and Juvas Khans "Influence of Metakaoline on the properties of mortar and concrete- Arevius applied clay services, March- 2009 " pp 393-400.

[17]. "Metakaoline and calcined clay as Pozzolonas for concrete-are view" cement and concrete composites. Dec 2001, PP 441-454.

[18]. BS EN: 206-1: "Concrete - Part I specifications, performance, production and conformity British Standard Institution, 2002."

[19]. IS 4031-1988: "Indian standard methods of physical test for hydraulic cement.

[20]. IS 1344-1968: "Indian standard specification for Pozzolonas" - bureau of Indian.

[21]. IS 2386-1963: "Indian standard methods for aggregates of concrete"- bureau of Indian standards, NEW DELHI.

[22]. IS 383-1970: "Indian standard specification on for coarse and fine aggregate for natural sources for concrete "- 2 revision bureau of Indian standards, New Delhi.

[23]. IS 516-1959: "Method of test for strength of concrete".

[24]. IS 7869 (part 2) 1981: Indian standard specification for admixtures for concrete.

[25]. IS 456 - 2000: Plain and reinforced concrete Indian standard specification. 